\title{
Biomask for skin regeneration
}

Keywords: biomask $\bullet$ burn $\bullet$ face $\bullet$ regeneration $\bullet$ restoration $\bullet$ scar $\bullet$ skin

\section{Critical challenges in facial skin wound healing}

The use of helmets and body armor in modern warfare greatly reduces the mortality and severity of injury for soldiers. However, facial injuries resulting from improvised explosive devices (IEDs), gun shots and burns are still common. Based on data from the Joint Theater Trauma Registry, craniomaxillofacial battle injuries to the head and neck were found in $42.2 \%$ of patients evacuated out of theater during the 10-year period covering operations Enduring Freedom and Iraqi Freedom for battle injuries [1]. Facial injury remains one of the greatest challenges in wound care [2]. The face is the most important identifiable feature of a human being, as it transmits feelings, expressions and emotions. The face also connects to many functional performances such as vision, smelling, breathing, kissing, eating and speech, among others. The treatment will greatly affect the quality of life and social integration of military soldiers [3]. The varied contours and continued/complex movement of the face has limited the use of a traditional wound vacuum-assisted closure (VAC) and the effectiveness of cut-to-fit skin substitutes $[4,5]$. Current treatment strategies following injuries often lead to scarring, infection, graft failures and poor cosmetic outcome. The scar reduction techniques, such as pulsed dye (e.g., $\mathrm{CO}_{2}$ ) laser therapy, z-plasty, or fatty tissue and stem cell injection, aim to make existing scars 'look and feel' better. The real challenge lays in prevention/reduction of scar formation in the first place. Restoration of aesthetic, functional facial skin in the first place has significant military and civilian impact, as well as huge cost benefit.

The key underlying challenges in facial skin wound healing are as follows:

- There is a lack of custom-made wound closure devices for the face. Early closure of the wound accelerates wound healing;

- Currently, there are no custom-made skin grafts that fit to the complex contour, shape and architecture of facial wounds. Instead, sheets of skin grafts are cut and stitched together to fit the face. The cut-to-fit skin grafts do not exactly fit the injured face. As a consequence of inadequate substrate adherence and inflammation, they universally lead to scarring (especially along the stitching line) [6];

- There is no custom-made wound VAC (negative pressure wound therapy) device adapted for the face. Wound VAC is a proven technology good for infection prevention, removal exodus and preparation of an optimal wound bed for grafting;

- There is an urgent need of skin regeneration technology specifically for the face. For example, after healing, even the autologous skin graft excised from the shoulder, back or chest looks different than regular facial skin [7].

\section{'Biomask' for skin regeneration}

To meet the urgent need for improved facial skin restoration outcomes, a team

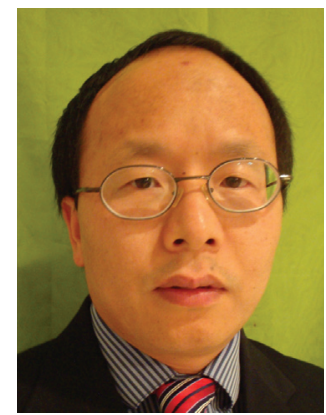

XingGuo Cheng ${ }^{\ddagger}$

Author for correspondence: xingguo.cheng@swri.org

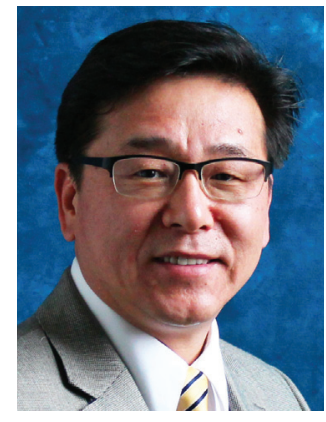

James J Yoo ${ }^{\ddagger}$

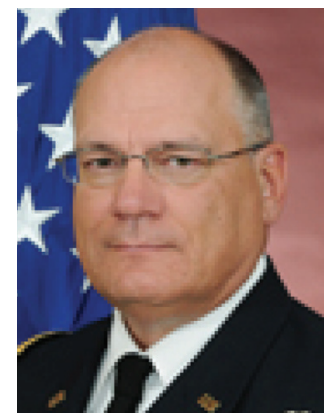

Robert G Hale ${ }^{\ddagger}$

${ }^{\ddagger}$ Authors contributed equally Please see page 248 for full affiliations.

Future $\%$ Medicine part of 
led by Col. Robert Hale at the US Army Institute of Surgical Research has proposed a 'Biomask' concept for wound management. The basic concept is to surface scan the patient's injured face for a stereolithography model $[8,9]$. Based on this model, a custom facial wound chamber/VAC can be made for the preparation of the wound bed for grafting. Next, a custom-made neodermal matrix that fits the face will be applied. Finally, after removal of the temporary epithelium layer, the vascularized facial dermis will be grafted with epithelium grafts and a custom face VAC applied to optimize graft take. Lastly, after graft take, stem cell-enriched fat can be injected beneath the neodermis to enhance favorable remodeling of the construct.

For the first step of the Biomask, the US Army Medical Research and Materiel Command has awarded a project to developing a pliable, polymer mask embedded with electrical, mechanical and biological components that can speed healing from disfiguring facial burns and help rebuild the faces of injured soldiers [10].

\section{"Biomask is ... distinctly different from a 'whole face transplant', which was performed in several cases in the world."}

Key to this whole Biomask concept is the second step, a custom facial neodermal matrix development. Ideally, a custom-made facial neodermal matrix will have the correct topography of the face and the correct thickness (e.g., thin on the eye lid, thick on the chin). The custom facial neodermal matrix will replace the current cut-to-fit skin graft sheets (e.g., INTEGRA ${ }^{\text {TM }}$ bilayer sheets [Integra LifeSciences Corporation, NJ, USA]). An engineering process can be used manipulate the flowable INTEGRA wound matrix or medical grade collagen precisely to a stereolithography model [11,12]. The custom facial dermis will be bilayered with a temporary siloxysilane covering. For example, the Armed Force Institute of Regenerative Medicine supports a project (AFIRM II), which specifically targets the development of the customized facial neodermal matrix.

For the third and final step of Biomask, multiple research projects involving skin regeneration are currently being supported by the AFIRM II program. These include: targeted, local delivery of drugs (e.g., statin, small molecule adhesion kinase inhibitor, novel peptide and polysacharide compound) to promote healing and reduce scarring [13]; nonimmunogenic stem cell therapy based on aminiotic fluid, stem cell dressing, new bilayer skin substitute (e.g., StrataGraft ${ }^{\circledR}$ [Stratatech Corporation, WI,
USA]) [14], autologous skin copying technology [15], pigmented autologous engineering skin and fat tissue injection $[16,17]$. Many of these developed technologies could be applied to the face, head, neck, hands and feet.

\section{Biomask is different from existing 'facial masks' or 'face transplant'}

The Biomask is conceptually different from current commercial face mask dressings such as the 'Dermaphase facial mask'. First, Biomask is a customized mask that fits to each individual, while the commercial compression polymer hydrogel Dermaphase facial mask fits to the face based on form fitting and flexibility of the polymer. Second, part or all of the Biomask material will integrate into the wound bed, facilitate vascularization and promote later grafting. On the other hand, the commercial compression polymer hydrogel Dermaphase facial mask is only temporarily used and needs to be peeled off (normally after 3-7 days). Finally, Biomask intends to be combined with custom negative pressure therapy and cell therapy for accelerated wound healing and skin restoration. On the other hand, the purpose of an elasto-gel facial mask is to temporarily prevent infection, absorb exodus and prevent dehydration. In essence, the Biomask performs much more functions than Dermaphase does. Biomask is also distinctly different from a 'whole face transplant', which was performed in several cases in the world [18].

\section{Direct 3D printing of skin wound matrix for the face is possible}

Recently, 3D printing technology was employed to deliver a skin wound matrix based on fibrin (with or without cells) to repair skin wounds in a porcine model. The portable bioprinter has a built-in laser scanner that scans the wound and determines its depth and area. The scan data is converted into 3D digital images that enable the device to determine the number of cell layers that need to be printed on the wound to restore its original configuration [19]. This system has successfully printed skin patches of $10 \mathrm{~cm}^{2}$ in a porcine excisional full-thickness skin defect model. In another study, stem cells derived from amniotic fluid were successfully printed to treat full-thickness skin wounds in mice [20].

One day, this skin printing technology may actually deliver cells and matrices directly onto burn victims. It is possible that the $3 \mathrm{D}$ printing technology can also help the Biomask concept. For example, a porous custom facial neodermis mask could be printed for direct grafting. 


\section{Restoration of functional aesthetic craniofacial envelope}

In conclusion, the concept of developing a customized Biomask is gradually being realized. The ultimate goal is the restoration of functional aesthetic craniofacial envelope (ReFACE). While there are numerous challenges that need to be addressed, successful development of individualized Biomasks would be a major leap in the treatment of burn in the craniofacial region. Furthermore, the technologies developed to create the Biomask for skin regeneration would facilitate applications in other areas of burn, such as the foot and hand (e.g., Biosock and Bioglove).

The Biomask for skin regeneration involves many multidisciplinary applied, preclinical and clinical researches. The research team includes biomedical engineers, electrical engineers, burn surgeons, research scientists, and so on. Based on the current efforts in addressing the challenges associated with maxillofacial injuries, it is expected that the levels of support from various organizations, including

\section{References}

1 Chan RK, Siller-Jackson A, Verrett AJ, Wu J, Hale RG. Ten years of war: a characterization of craniomaxillofacial injuries incurred during operations Enduring Freedom and Iraqi Freedom. J. Trauma Acute Care Surg. 73(6), S453-S458 (2012).

2 Leon-Villapalos J, Jeschke MG, Herndon DN. Topical management of facial burns. Burns 34(7), 903-911 (2008).

3 Hoogewerf CJ, Van Baar ME, Middelkoop E, Van Loey NE. Impact of facial burns: relationship between depressive symptoms, self-esteem and scar severity. Gen. Hosp. Psychiatry 36(3), 271-276 (2014).

4 Runkel N, Krug E, Berg L et al. Evidence-based recommendations for the use of negative pressure wound therapy in traumatic wounds and reconstructive surgery: steps towards an international consensus. Injury 42(Suppl. 1), S1-S12 (2011).

5 Sahin I, Eski M, Acikel C, Kapaj R, Alhan D, Isik S. The role of negative pressure wound therapy in the treatment of fourth-degree burns. Trends and new horizons. Ann. Burns Fire Disasters 25(2), 92-97 (2012).

6 Horch RE, Jeschke MG, Spilker G, Herndon DN, Kopp JR. Treatment of second degree facial burns with allografts - preliminary results. Burns 31(5), 597-602 (2005).

7 Wood D. Beyond the battlefield: new hope, but a long and painful road for veterans pulled from death's grasp. www.huffingtonpost.com/2011/10/17/beyond-thebattlefield-6-new-hope_n_1005090.html?page $=1$

8 Rogers B, Chapman T, Rettele J et al. Computerized manufacturing of transparent face masks for the treatment of facial scarring. J. Burn Care Rehabil. 24(2), 91-96 (2003). the Department of Defense, would continue to increase in the coming years. It is expected that some of these projects will result in successful medical devices, drugs, combination therapies and innovative cutting-edge interventions.

\section{Disclaimer}

The views expressed in this manuscript do not necessarily reflect the position or the policy of the Government, and no official endorsement should be inferred.

\section{Financial \& competing interests disclosure}

The authors wish to acknowledge support from the Armed Forces Institute of Regenerative Medicine (Award \#W81XWH-13-2-0054), which is awarded and administered through the US Army Medical Research Acquisition Activity. The authors have no other relevant affiliations or financial involvement with any organization or entity with a financial interest in or financial conflict with the subject matter or materials discussed in the manuscript apart from those disclosed.

No writing assistance was utilized in the production of this manuscript.

9 Sabol JV, Grant GT, Liacouras P, Rouse S. Digital image capture and rapid prototyping of the maxillofacial defect. J. Prosthodont. 20(4), 310-314 (2011).

10 Regenerative and reconstructive technologies. www.uta.edu/utari/research/biomedical-technologies/ regenerative.php

11 Cheng XG, Ben A, Ling J. Electrochemical aligned collagen sheet cultured with mesenchymal stem cells (MSCs) for potential skin tissue regeneration applications. Presented at: Tissue Engineering and Regenerative Medicine (Termis) Conference. Houston, TX, USA, 14 December 2011.

12 Southwest Research Institute: US20110306754 (2010).

13 Lin F, Zhu J, Tonnesen MG et al. Fibronectin peptides that bind PDGF-BB enhance survival of cells and tissue under stress. J. Invest. Dermatol. 134(4), 1119-1127 (2014).

14 Centanni JM, Straseski JA, Wicks A et al. StrataGraft skin substitute is well-tolerated and is not acutely immunogenic in patients with traumatic wounds: results from a prospective, randomized, controlled dose escalation trial. Ann. Surg. 253(4), 672-683 (2011).

15 Tam J, Wang Y, Farinelli WA et al. Fractional skin harvesting: autologous skin grafting without donor-site morbidity. Plast. Reconstr. Surg. Glob. Open 1(6), e47 (2013).

16 Natesan S, Wrice NL, Baer DG, Christy RJ. Debrided skin as a source of autologous stem cells for wound repair. Stem Cells 29(8), 1219-1230 (2011).

17 Grahovac TL, Rubin JP. Discussion: an analysis of the experiences of 62 patients with moderate complications after full-face fat injection for augmentation. Plast. Reconstr. Surg. 129(6), 1369-1370 (2012). 
18 Zhao JH, Diao JS, Xia WS, Pan Y, Han Y. Clinical application of full-face, whole, full-thickness skin grafting: a case report. J. Plast. Reconstr. Aesthet. Surg. 65(11), 1576-1579 (2012).

19 Edwards L. 3D bioprinters to print skin and body parts. http://phys.org/news/2011-2002-3d-bio-printers-skinbody.html

20 Skardal A, Mack D, Kapetanovic E et al. Bioprinted amniotic fluid-derived stem cells accelerate healing of large skin wounds. Stem Cells Transl. Med. 1(11), 792-802 (2012).

\section{Affiliations}

\section{- XingGuo Cheng}

Microencapsulation \& Nanomaterials Department, Southwest Research Institute, 6220 Culebra Road, San Antonio, TX 78238, USA

\section{- James J Yoo}

Wake Forest Institute for Regenerative Medicine, Medical Center Boulevard Winston-Salem, NC 27157, USA

\section{- Robert G Hale}

Colonel, Dental Corps Commander, US Army Dental \& Trauma Research Detachment, US Army Institute of Surgical Research, 3698 Chambers Pass Suite B, Fort Sam Houston, TX 78234, USA 